\title{
Chronic stress-induced alterations in amygdala responsiveness and behavior - modulation by trait anxiety and corticotropin-releasing factor systems
}

\author{
Carmen Sandi, ${ }^{1}$ M. Isabel Cordero, ${ }^{1}$ Annarosa Ugolini, ${ }^{2}$ Emilio Varea, ${ }^{1}$ Laura Caberlotto ${ }^{2}$ and Charles H. Large ${ }^{2}$ \\ ${ }^{1}$ Laboratory of Behavioral Genetics, Brain Mind Institute, Ecole Polytechnique Federale de Lausanne (EPFL), Bat. AAB, Station 15, \\ $\mathrm{CH}-1015$ Lausanne, Switzerland \\ ${ }^{2}$ Medicines Research Centre, GlaxoSmithKline S.p.A., Verona, Italy
}

Keywords: corticotropin-releasing factor receptor 1, corticotropin-releasing factor receptor 1 antagonism, depression, rat

\begin{abstract}
The basolateral nucleus of the amygdala (BLA) plays a key role in emotional arousal and anxiety, and expresses high levels of corticotropin-releasing factor receptor (CRFR)1. In rat brain slices, we have recently shown that afferent activation of the BLA is increased following application of exogenous corticotropin-releasing factor (CRF). Here we examined the impact of chronic unpredictable stress (CUS) on this effect of CRF and whether blockade of CRFR1 could prevent stress-induced changes in the electrophysiological response, the animal's behavior and in cell proliferation in the hippocampus. The behavior of the rats was monitored via a series of tests that formed part of the CUS. Electrophysiological measures of the BLA response to CRF, cell proliferation in the dentate gyrus and the expression of CRF and CRFR1 mRNA in amygdaloid nuclei were determined ex vivo after completion of the CUS. CRF-induced potentiation of afferent activation of the BLA was reduced in rats exposed to CUS, an effect that was inhibited by chronic antagonism of CRFR1. Furthermore, the reduction in BLA response to CRF was correlated with the anxiety trait of the animals, determined prior to initiation of the CUS. These results implicate CRFR1 in chronic stress-induced alterations in amygdala function and behavior. Furthermore, they show that CRFR1 antagonists can prevent changes induced by chronic stress, in particular in those animals that are highly anxious.
\end{abstract}

\section{Introduction}

Corticotropin-releasing factor (CRF) is an essential mediator of the behavioral, endocrine and autonomic responses to stress (Dunn \& Berridge, 1990). The effects of CRF are mediated by two receptors, corticotropin-releasing factor receptor (CRFR)1 and CRFR2, with the former most abundant in the central nervous system. Strong evidence supports a key role for the dysregulation of CRF pathways in anxiety and depression in humans (Holsboer, 1999; Van Den Eede et al., 2005) and animals (Dunn \& Berridge, 1990; Koob \& Heinrichs, 1999).

The central nucleus of the amygdala (CeA) is the major extrahypothalamic location of CRF-containing neurons that release CRF in response to stress (Merlo Pich et al., 1995). The basolateral nucleus of the amygdala (BLA) has been shown to play a key role in emotional arousal and stress-induced, CRF-mediated modulation of cognitive processes (Roozendaal et al., 2002, 2004; McGaugh, 2004). Magnocellular neurons in the BLA express high levels of CRFR1 (Chen et al., 2000; Van Pett et al., 2000) and project to areas such as the hippocampus, where they contribute to the consolidation of emotional memories (Paré, 2003). Activation of CRFR1 was shown to increase

Correspondence: Professor C. Sandi, as above.

E-mail: carmen.sandi@epfl.ch

Received 16 May 2008, revised 18 July 2008, accepted 8 August 2008 the excitability of these projection neurons (Rainnie et al., 1992) and thus the release of CRF in the BLA has been postulated to contribute to stress-induced alterations in affective behavior, including anxiety states linked to chronic stress (Rainnie et al., 2004). Consistent with this hypothesis, repeated activation of the BLA or repetitive administration of subthreshold doses of CRF results in altered sensitivity of BLA neurons to further stimulation and the development of a chronic anxiety-like state (Sajdyk et al., 1999).

We recently found that the amplitude of field post-synaptic potentials (fPSPs) recorded in the BLA and evoked by stimulation of the lateral nucleus of the amygdala was increased following application of exogenous CRF (Ugolini et al., 2008). The effect was mediated by CRFR1 and by downstream activation of protein kinase $\mathrm{C}$, and is reminiscent of CRF-induced long-term potentiation observed in the hippocampus, which is also mediated by CRFR1 (Blank et al., 2002). The effect was also consistent with neurochemical (Dube et al., 2000) and electrophysiological (Rainnie et al., 2004) evidence that indicated an activation of the BLA following in-vivo central (intracerebroventricular or intra-amygdala) administration of CRF. In the present study, we used a chronic unpredictable stress (CUS) model in rats to evaluate whether the responsiveness of the BLA to CRF might be affected by stress. In parallel, we examined the behavior of animals exposed to the CUS via tests that formed part of the unpredictable stress procedure. We hypothesized that 
the CUS procedure might blunt the electrophysiological response of the BLA to exogenous CRF and that this would be associated with behavioral changes in the animals. In order to determine whether electrophysiological and/or behavioral changes were associated with altered expression of the CRF system, we also investigated the impact of CUS on the expression of CRFR1 and CRF peptide mRNA in the amygdala.

Antagonists of CRFR1 can reduce the stress-induced behavioral response in rodent models of depression (Arborelius et al., 1999, 2000; Bale \& Vale, 2003). Moreover, a non-peptide CRFR1 antagonist, 3-[6(dimethylamino)-4-methyl-pyrid-3-yl]-2,5-dimethyl- $N, N$-dipropyl-pyrazolo[2,3-a]pyrimidin-7-amine (NBI30775) (also known as R121919), has been shown to have beneficial effects on depressive symptoms in patients (Zobel et al., 2000). Therefore, in a further experiment, we examined the ability of this antagonist, when given chronically during the CUS procedure, to prevent electrophysiological and behavioral changes. In addition, as reductions in hippocampal neurogenesis and cell proliferation have been repeatedly associated with chronic stress and depression (Duman, 2004), we also examined changes in cell proliferation in the dentate gyrus following CUS and the ability of NBI30775 to prevent any changes that might be seen.

Finally, although chronic stress is likely to contribute to the development of depression, there is considerable variability in the susceptibility of individuals to the adverse effects of stress. Individual differences in personality traits are associated with both resilience to stress and stress-induced depression (Southwick et al., 2005; Levinson, 2006). In particular, the neuroticism/anxiety trait is an important risk factor for the development of depression (Ball \& Schottenfeld, 1997; Wang et al., 2002). Consequently, as a secondary aim of these studies, we examined the relationship between CUS-induced electrophysiological and behavioral changes and the anxiety trait of individual animals. Anxiety trait was assigned on the basis of the behavior of each animal observed during an elevated plus maze (EPM) task 1 week prior to the start of the CUS procedure. In this case, we hypothesized that a greater impact of the CUS on electrophysiological and behavioral measures might be observed in animals defined as having high trait anxiety.

\section{Materials and methods}

\section{Subjects}

Adult male Sprague-Dawley rats (Charles River Laboratories) were used. Animals were housed individually and maintained under lightand temperature-controlled conditions. Animal care procedures were approved through a license issued by the Cantonal Veterinary Authorities (Vaud, Switzerland) and were consistent with GlaxoSmithKline's guidelines for the care and use of animals in research.

\section{General experimental paradigm}

At 2 weeks after arrival, rats were handled daily for 3 days. They were then tested in the EPM to determine individual anxiety level. Subsequently, rats were matched according to their body weight and anxiety level, and randomly assigned to the different experimental groups (two or four depending on the specific experiment). The CUS protocol lasted 3 weeks, starting 1 week after the EPM. At $24 \mathrm{~h}$ after the last CUS day, rats were anaesthetised with pentobarbital $(50 \mathrm{mg} / \mathrm{kg}$ i.p.) and either decapitated and brains removed for amygdala electrophysiology or perfused in $4 \%$ paraformaldehyde in $0.1 \mathrm{M}$ phosphate buffer for immunohistochemistry procedures.

Behavioral indexes of the impact of CUS were evaluated through responses obtained during the CUS: (i) contextual fear conditioning on days 20 and 21; and (ii) a forced swimming test on days 7 and 14 .

\section{EPM}

Anxiety-related behaviors were evaluated using the EPM test (Herrero et al., 2006). Briefly, the test consists of two opposing open arms $(45 \times 10 \mathrm{~cm})$ and two enclosed arms $(45 \times 10 \times 50 \mathrm{~cm})$ that extend from a central platform $(10 \times 10 \mathrm{~cm})$, elevated $65 \mathrm{~cm}$ above the floor. The rats were placed individually on the central platform and allowed to explore the maze for $5 \mathrm{~min}$. Behavior was monitored using a video camera and analysed with a computerized tracking system (Ethovision 3.1.16, Noldus IT, The Netherlands). Time spent in the open and closed arms (and their edges) was recorded. Subsequently, and for each experiment, rats were classified according to the time they spent in the open arms of the maze as high anxiety (HA) when values were below the mean of the whole population of rats tested and low anxiety (LA) when values were above the mean.

\section{CUS}

During the course of 3 weeks, rats were exposed daily to various stressors that were applied at different times of the day and included: bright light (300 lx, $30 \mathrm{~min})$, elevated platform $(2 \mathrm{~h})$, predator odor ( $1 \mathrm{~h}$ exposure to $10 \mu \mathrm{L}$ of trimethylthiazoline, a synthetic compound originally isolated from fox feces), contextual fear conditioning (three $1 \mathrm{~s}$ shocks of $0.4 \mathrm{~mA}$ ) followed by a subsequent test session (exposure to context associated with shocks, see below for more detailed methods), acoustic stimulation (78-115 dB noise bursts), forced swim test in tanks of different sizes (see below for detailed methods), exposure to a novel arena, and an EPM (similar to that described above to assess anxiety trait).

\section{Contextual fear conditioning}

Rats were trained using three $1 \mathrm{~s}$ footshocks of $0.4 \mathrm{~mA}$ intensity in a rodent observation cage on day 20 and tested by being placed into the same chamber for $5 \mathrm{~min}$ in the absence of shocks on day 21. Freezing behavior during the test session was captured by a video camera and was defined as behavioral immobility except for movement needed for respiration. Video recordings were analysed blind to treatment with the assistance of a computer program (The Observer 5.0.25, Noldus IT, 2003). For comparison, a group of naive, undisturbed rats was trained in the same contextual fear conditioning procedure to provide a control.

\section{Forced swimming test}

Rats were submitted to two $10 \mathrm{~min}$ forced swim sessions on days 7 and 14. Rats were individually placed in a plastic beaker $(25 \mathrm{~cm}$ diameter, $46 \mathrm{~cm}$ deep) containing $30 \mathrm{~cm}$ of water $\left(25 \pm 1^{\circ} \mathrm{C}\right)$ for $10 \mathrm{~min}$. Behavior was recorded with a video camera and the time spent immobile (making only those movements necessary to keep the nose above the water), swimming, climbing and diving was recorded manually using a computer program (THE OBSER VER 5.0.25, Noldus IT, 2003).

\section{Electrophysiological studies}

In-vitro brain slices were obtained $24 \mathrm{~h}$ after rats were submitted to the last CUS session. One control and one stressed rat were studied on each day in an experimenter-blind manner and one to three amygdala slices were examined for each animal. Rats were anesthetized with pentobarbital (50 mg/kg i.p.) and decapitated. The brain was removed and cooled rapidly in a modified artificial cerebrospinal fluid solution 
$\left(0-6^{\circ} \mathrm{C}\right)$ bubbled continuously with $95 \% \mathrm{O}_{2}$ and $5 \% \mathrm{CO}_{2}$ to maintain physiological $\mathrm{pH}(7.35-7.45)$. Slices $(400 \mu \mathrm{M})$ were cut in the horizontal orientation on a Vibroslice (Campden Instruments) and transferred to a holding chamber containing artificial cerebrospinal fluid at room temperature $22 \pm 1^{\circ} \mathrm{C}$. After at least $1 \mathrm{~h}$, a slice was transferred to the recording chamber, where it was fully submerged and continuously perfused with oxygenated artificial cerebrospinal fluid maintained at $33 \pm 1{ }^{\circ} \mathrm{C}$.

Glass microelectrodes containing $154 \mathrm{mM} \mathrm{NaCl}$ (resistance 3-8 M $\Omega$ ) were placed within the BLA visually and then adjusted to record the best field potential. Extracellular field potentials were evoked by electrical stimulation delivered to the lateral nucleus of the amygdala $(0.05 \mathrm{~Hz}, 0.1 \mathrm{~ms}$ duration) with a bipolar electrode. The potentials were amplified (Axoprobe-1A, Axon Instruments) and acquired using a National Instruments interface and custom software. A stimulation current sufficient to evoke a response that was $50-60 \%$ of the maximum was used unless otherwise indicated. Drugs were applied by bath perfusion in the artificial cerebrospinal fluid and introduced to the recording chamber at a flow rate of $2 \mathrm{~mL} / \mathrm{min}$. The amplitude of the second negative-going fPSP of evoked BLA field potentials was measured as described by Ugolini et al. (2008).

\section{Drugs}

The CRFR1 antagonist NBI30775 was a gift from Neurocrine Inc. It was administered subcutaneously at $10 \mathrm{mg} / \mathrm{kg}$ in $4 \% \mathrm{v} / \mathrm{v}$ dimethylsulfoxide $/ 0.5 \% \mathrm{w} / \mathrm{v}$ methocell, $1 \mathrm{~h}$ before the application of the stressor on each day of the CUS or at the corresponding time in the non-stressed control group. Vehicle was administered in a similar manner to stressed and non-stressed groups. For the electrophysiological experiments, human/rat CRF was used (Sigma-Aldrich, St Louis, MO, USA).

\section{Immunohistochemistry}

\section{Ki67 and CRFR1 immunohistochemistry}

Tissue was processed 'free-floating' for immunohistochemistry. After washing, sections were incubated with $10 \%$ methanol and $3 \% \mathrm{H}_{2} \mathrm{O}_{2}$ in phosphate-buffered saline (PBS) for 10 min to block endogenous peroxidase activity. They were then treated for $1 \mathrm{~h}$ with $5 \%$ normal donkey serum (Jackson Laboratories) in PBS with $0.2 \%$ Triton$\mathrm{X} 100$ (Sigma) and incubated overnight at room temperature in either mouse monoclonal IgG anti-Ki67 (1:200, Novocastra) or goat polyclonal IgG anti-CRFR1 (1 : 5000, Santa Cruz). After washing, sections were incubated for $30 \mathrm{~min}$ with donkey anti-mouse or donkey anti-goat IgG biotinylated antibodies (Jackson Laboratories, $1: 250$ ) followed by an avidin-biotin-peroxidase complex (ABC, Vector Laboratories) for $30 \mathrm{~min}$ in PBS. Color development was achieved by incubating with 3,3'-diaminobenzidine tetrahydrochloride (Sigma) for $4 \mathrm{~min}$. PBS containing $0.2 \%$ Triton-X100 and 3\% normal donkey serum (NDS) was used for primary and secondary antibody dilution. All sections passed through all procedures simultaneously to minimize any variability arising from immunohistochemical procedures. The number of Ki67-expressing cells in the $100 \%$ dentate gyrus was estimated using a modified version of the fractionator method (West, 1993). Cell somata were identified and counted with a $40 \times$ objective. Cells appearing in the upper focal plane were omitted to prevent counting cell caps. The volume of areas analysed was determined for each animal using Cavalieri's principle (Gundersen \& Jensen, 1987).

\section{Double immunofluorescence}

Double immunohistochemistry using anti-CRFR1 antibody and antibodies against neuronal nuclear protein $(\mathrm{NeuN})$ and $\mathrm{Ki67}$ was performed to assess whether the CRFR1 was expressed in newly generated or mature neurons. In general, sections were processed as described above but the endogenous peroxidase block was omitted. The sections were incubated overnight with goat polyclonal IgG antiCRFR1 (Santa Cruz, 1: 5000, sc-1757) and one of the following primary antibodies: mouse monoclonal anti-NeuN (1 : 200, Chemicon) or mouse monoclonal anti-Ki67 (1:200, Novocastra). After washing, sections were incubated with donkey anti-goat $\operatorname{IgG}$ and donkey anti-mouse $\operatorname{IgG}$ secondary antibodies conjugated with Alexa 488 or Alexa 555 (Molecular Probes, 1 : 200) in PBS containing $0.2 \%$ Triton X-100 and 3\% NDS. All sections were observed under a confocal microscope (Leica TCS-SP2). Z-series of optical sections ( $1 \mu \mathrm{m}$ apart) were obtained using sequential scanning mode. These stacks were processed with LSM 5 IMAGE BROWSER software. NeuNand Ki67-immunoreactive cells were first identified using conventional fluorescence microscopy. A stack of confocal images covering all of its three-dimensional extension was then taken to confirm the labelling for the CRFR1 antibody. Fifty immunoreactive cells for each marker were analysed.

\section{In-situ hybridization}

Riboprobes specific for the rat CRF and CRFR1 mRNA were used. Before hybridization, labeled probe was added to the hybridization cocktail. After hybridization, slides were air dried and exposed to Fuji Imaging plates (BAS-TR 2025) together with ${ }^{14} \mathrm{C}$ standards. Semiquantitative analyses were performed on the in-situ hybridization images. Light transmittance values were measured from the digitalized images using an image analysis software system (AIS 4.0, Imaging Research, St Catharines, Canada). Based on the known radioactivity of the standards relative to their transmittance levels, the light transmittance values phospho-stimulated luminescence (PLS) per $\mathrm{mm}^{2}$ were converted to $\mathrm{nCi} / \mathrm{g}$ using a calibration curve. The regions of interest were defined by anatomical landmarks in conjunction with a rat brain atlas (Paxinos \& Watson, 1998). For each animal, two consecutive sections were considered and the regions were analysed bilaterally. The measurements of each specific brain region were taken by individually tracing the structures on the TV monitor with a cursor.

\section{Statistics}

Data (except for correlational analyses) are expressed as mean \pm SEM. Statistical analyses of data included Student's $t$-test for paired or unpaired samples, as appropriate, ANOVA (one-way, factorial and/or repeated measures, as appropriate), followed by Fisher's Protected least significant difference (PLSD) post-hoc tests and Pearson's correlation.

\section{Results}

The impact of chronic stress on the effect of CRF on ex-vivo electrophysiological responses in the BLA and on stress-related behaviors - correlations with trait anxiety

In a first experiment, five control rats and five rats submitted to CUS were studied. The impact of the CUS procedure was determined by examining body weight gain during the 3 weeks of stress exposure. As expected, animals submitted to CUS showed a significant reduction in body weight gain (\% Gain: Control group: 1st week, $133.46 \pm 1.92$; 
A)

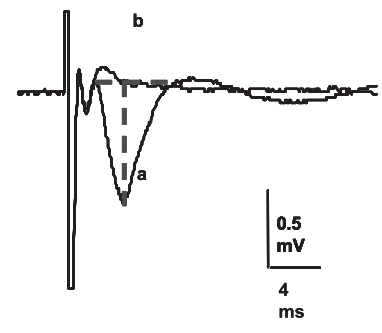

C)

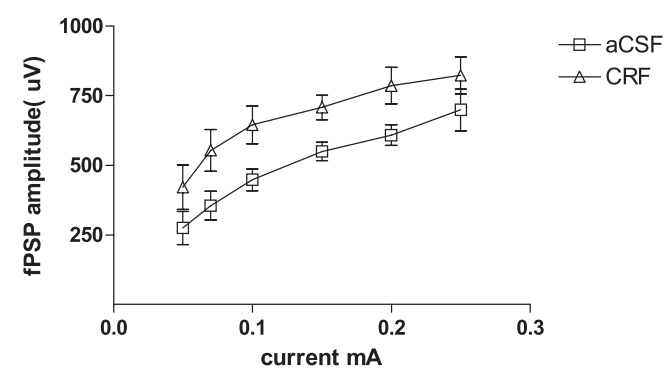

E)

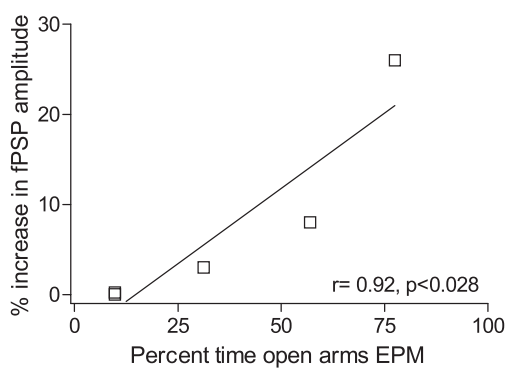

B)

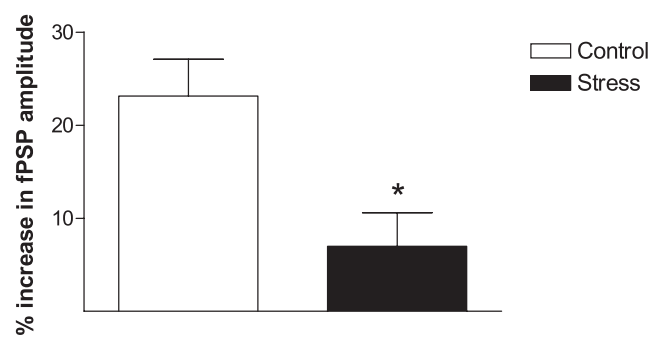

D)

STRESSED rats

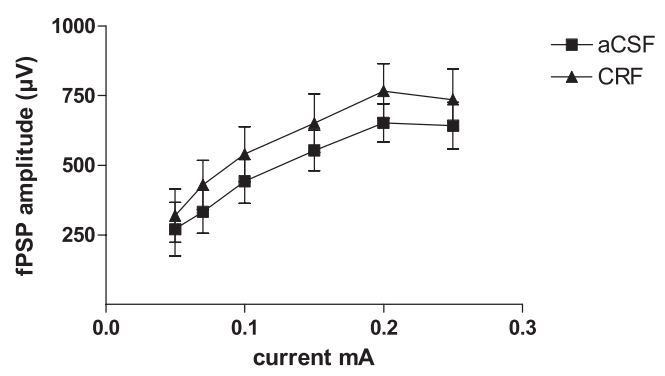

F)

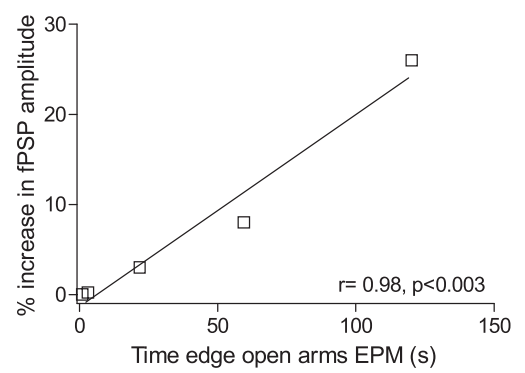

FIG. 1. Impact of chronic stress on the effect of CRF on ex-vivo electrophysiological responses in the BLA and correlations with trait anxiety. (A) A characteristic field response recorded in the BLA following stimulation of the lateral amygdala in normal artificial cerebrospinal fluid (aCSF) (a) and in the presence of 6-cyano7-nitroquinoxaline-2,3-dione (CNQX) (10 $\mu \mathrm{M})(\mathrm{b})$. A short-latency negative-going field potential is followed by a second, longer latency, negative-going potential (fPSP). The second component of the response is blocked completely by the $\alpha$-amino-3-hydroxy-5-methylisoxazole-4-propionate/kainate receptor antagonist, CNQX. All results refer to this component, whose amplitude was measured as shown by the dotted lines. (B) Histogram showing the effect of CRF (0.1 $\mu \mathrm{M})$ on the amplitude of fPSPs evoked in control slices or slices taken from rats submitted to CUS. Current-response relationship for evoked fPSPs in the absence (I) and presence (?) of CRF $(0.1 \mu \mathrm{M})$ in slices taken from (C) control rats and (D) stressed rats. Results are the mean \pm SEM from seven slices from five rats in each group. (E) Positive correlation between an anxiety measure (percent time spent in the open arms of the EPM during the pre-stress testing) and the percent CRF-induced increase in fPSP amplitude in animal submitted to CUS. (F) Similar correlation as in E, this time between the percent time spent at the edge of the open arms and the percent CRF-induced increase in fPSP amplitude in animals submitted to CUS. $* P<0.05$.

2nd week, $143.73 \pm 2.28 ; 3$ rd week, $150.34 \pm 2.47$; CUS group: 1 st week, $124.28 \pm 1.54 ; \quad$ 2nd week, $134.33 \pm 1.60 ; \quad 3$ rd week, $138.62 \pm 1.76 \%$; repeated measures ANOVA: $\left.F_{1,8}=14.04, P<0.006\right)$.

In slices from control rats, stimulation of the lateral amygdala evoked a short latency $(1 \mathrm{~ms})$ negative-going field potential in the BLA (Fig. 1A), which is presumed to reflect a pre-synaptic fibre volley and/or direct activation of neurons within the BLA (Isoardi et al., 2004), and which could be inhibited by tetrodotoxin (100 nM; data not shown). This was followed by a second, longer latency (2$3 \mathrm{~ms}$ ) negative-going fPSP that could be inhibited by application of the $\alpha$-amino-3-hydroxy-5-methylisoxazole-4-propionate/kainate receptor antagonist, 6-cyano-7-nitroquinoxaline-2,3-dione (10 $\mu \mathrm{M}$,
Fig. 1A), and is presumed to reflect the post-synaptic response of predominantly pyramidal neurons in the BLA (Isoardi et al., 2004). Application of CRF $(0.1 \mu \mathrm{M})$ to slices $(n=7)$ obtained from unstressed, control rats enhanced the amplitude of the longer latency synaptic response by $23 \pm 4 \%$ but had no effect on the early response (Fig. 1B). However, in slices $(n=7)$ from rats submitted to CUS, the enhancement of the fPSP amplitude by CRF was significantly smaller $(7 \pm 4 \%, t=3.01$, d.f. $=12, P<0.05$; Fig. 1B).

Analysis of the current-response relationship in the absence and presence of CRF showed that, in non-stressed control rats, the peptide increased the amplitude of the fPSP over a range of stimulus intensities (repeated measures ANOVA: main effect of CRF, 
$F_{1,72}=8.1, \quad P<0.015 ;$ main effect of current, $F_{6,72}=138.0$, $P<0.0001$; interaction between current and CRF, $F_{6,72}=2.65$, $P<0.02$; Fig. 1C) but this was not the case in stressed rats [repeated measures ANOVA: main effect of current, $F_{6,72}=85.0, P<0.0001$; no effect of CRF, $F_{1,72}=0.36$, not significant (n.s.); no interaction between current and CRF, $F_{6,72}=0.63$, n.s.; Fig. 1D].

We hypothesized that anxiety trait would modulate the impact of chronic stress. In particular, we evaluated whether anxiety trait (determined from a baseline EPM conducted 1 week before CUS) might predict the degree of effect of CRF on electrophysiological responses in the BLA. No correlation was observed between EPM measures and electrophysiological response to CRF in control rats (n.s.; data not shown). However, in chronically stressed animals, the time spent in the open arms $(r=0.92, P<0.03$; Fig.1E) and the time spent near the edge of the open arms $(r=0.98, P<0.003$; Fig. 1F) during the EPM test were significantly correlated with the subsequent effect of CRF on fPSP amplitude in the BLA; the higher the trait anxiety, the lower the facilitation of fPSP responses by CRF.

At the behavioral level, the ability of CUS to produce emotional and/or learning alterations was verified by assessment of behavioral changes in two tests performed as part of the CUS procedure: contextual fear conditioning (days 20 and 21) and forced swimming test (days 7 and 14). In agreement with previous reports (Sandi et al., 2001; Cordero et al., 2003), chronically stressed rats $(n=5)$ froze significantly more than a group of naive control rats $(n=6)$ during the test session $(t=2.4$, d.f. $=9, P<0.04$; Fig. 2A), indicative of a stress-induced enhancement of conditioned fear. This effect cannot be attributed to an altered sensitivity to the shock in the stress group as post-shock freezing during the training session did not differ between the two groups $(t=0.66$, d.f. $=9$, n.s.). We further determined whether there might be a correlation between the degree of freezing observed during the $24 \mathrm{~h}$ test session in the stress group and the percent increase in fPSP amplitude recorded following CRF stimulation in vitro; however, a Pearson test failed to show a significant correlation $(r=-0.53$, $P=0.36$; Fig. 2B). Behavior in the forced swim test performed on days 7 and 14 of the CUS was also analysed. A significant increase was observed in the percentage of time spent floating on day 14 $(72.34 \pm 4.68 \%)$ compared with day $7(50.92 \pm 2.03 \%)(t$-test paired samples: $t=4.10$, d.f. $=4, P<0.015)$, with the increase particularly evident over the first $5 \mathrm{~min}$ of the test $(t=3.49$, d.f. $=4, P<0.025$; Fig. 2C). Moreover, a significant correlation was found between the percent increase in immobilization from day 7 to day 14 and the percent increase in fPSP amplitude following CRF stimulation in vitro $(r=-0.878, P<0.05$; Fig. 2D).
A)

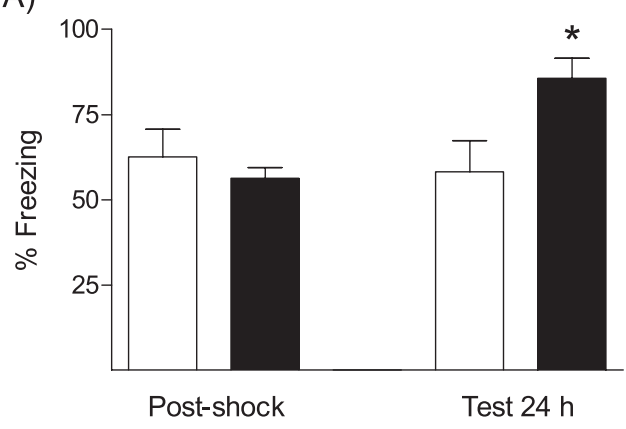

C)

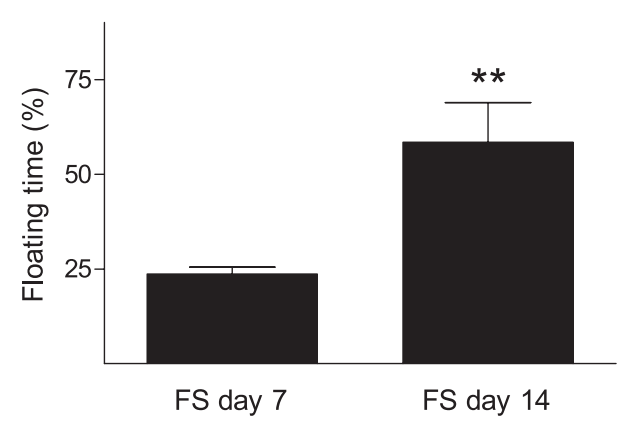

\section{$\square$ Control}

B)

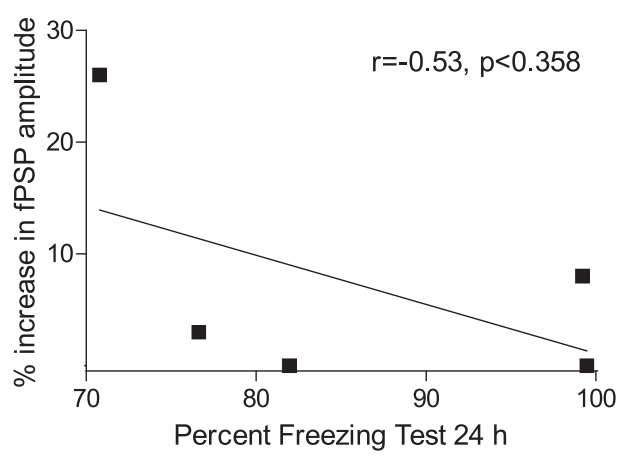

D)

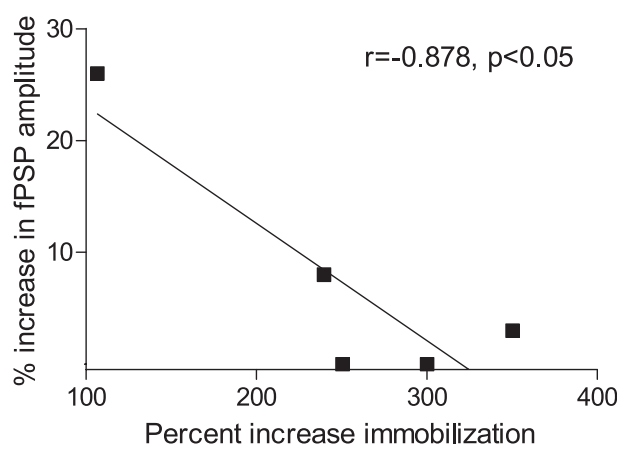

$\square$ Stress

FIG. 2. Impact of CUS on stress-related behaviors. (A) Contextual fear conditioning performed on days 20 and 21 of the CUS; stressed animals spent more time freezing during the retention test (Test $24 \mathrm{~h}$ ) than controls. (B) Lack of significant correlation between the percent freezing during the $24 \mathrm{~h}$ test and the percent increase in fPSP amplitude in the BLA following CRF stimulation. (C) Forced swimming test (FS) performed on days 7 and 14 of the CUS; in stressed animals, an increase in the percent time floating during FS was increased from the first (day 7) to the second (day 14) exposure. (D) Significant negative correlation between the percent increase in immobilization displayed by animals in the FS on day 14 as compared with day 7 . Results in A and C are the mean \pm SEM. $* P<0.05$ vs. control; $* * P<0.01$ vs. FS day 7 . 


\section{The impact of chronic stress on amygdaloid CRF systems according to anxiety trait}

Given that the impact of CUS on the electrophysiological response to CRF in the BLA was correlated with trait anxiety, we ran a second experiment to examine the effects of CUS on endogenous levels of CRFR1 and CRF peptide in the amygdala in rats classified as HA and LA.

Rats $(n=24)$ were first classified according to their behavior in the EPM as either HA ( $n=14$; open arms, $2.72 \pm 0.84 \%)$ or LA $(n=10$; open arms, $18.31 \pm 2.70 \%$ ). Pairs of rats within each anxiety group were then matched and equally distributed into the control (HA, $n=7$; LA, $n=5$ ) and stress (HA, $n=7$; LA, $n=5$ ) groups. Once again, the CUS procedure resulted in reduced body weight gain compared with unstressed rats (\% Gain: Control group: 1st week, $111.61 \pm 0.70 ; 2$ nd week, $118.85 \pm 1.16$; 3 rd week, $124.39 \pm 1.20$; CUS group: 1 st week, $124.28 \pm 1.54$; 2nd week, $114.24 \pm 1.48$; 3rd week, $122.29 \pm 1.10 \%$ ). A two-way repeated measures ANOVA found a main effect of stress $\left(F_{1,20}=4.83, P<0.04\right)$ and a trend towards a main effect of anxiety trait $\left(F_{1,20}=3.49, P=0.076\right)$ on body weight gain.

In order to compare the impact of CUS on amygdala CRFR1 mRNA between HA and LA groups, a two-way repeated measures ANOVA was performed with anxiety trait and stress as between-subject factors, and amygdala nucleus as a within-subject factor. No significant main effect of anxiety trait or stress was observed (Stress: $F_{1,20}=1.22$, n.s.; Anxiety trait: $F_{1,20}=0.16$, n.s.). There were also no significant interactions between either anxiety trait or stress and amygdala nucleus, or between all three factors (Stress $\times$ Anxiety $\times$ Amygdala: $F_{2,40}=0.76$, n.s.). However, a significant interaction between stress and anxiety trait was found $\left(F_{1,20}=4.56, P<0.045\right)$. Post-hoc analyses revealed that, in the absence of stress, there was a trend for HA rats to show higher expression of CRFR1 mRNA in the amygdala nuclei analysed compared with LA rats $(P<0.088)$. However, stress significantly reduced the expression of CRFR1 mRNA in the amygdala of HA rats $(P<0.021)$. This reduction was not observed in LA rats. As might be expected, there was also a significant main effect of amygdala nucleus $\left(F_{2,40}=19.55\right.$, $P<0.001)$. Therefore, further analyses were performed for each nucleus. Although no significant main effect of any of the factors was observed, significant interactions between anxiety trait and stress were found in the CeA $\left(F_{1,20}=7.77, P<0.011\right)$ and medial nucleus of the amygdala $\left(F_{1,20}=4.93, P<0.038\right)$. Post-hoc analyses confirmed that CRFR1 mRNA expression in non-stressed rats differed according to trait anxiety, with HA rats showing higher levels of expression than LA rats (CeA, $P<0.04$; medial nucleus of the amygdala, $P=0.06$ ). Post-hoc analyses also showed that stress was associated with a significant reduction in CRFR1 mRNA expression in HA rats (control vs. stress: CeA, $P<0.008$; medial nucleus of the amygdala, $P<0.033$ ) but not LA rats.

Analysis of the expression of CRF peptide mRNA in the CeA (Fig. 3B) indicated a lack of effect of stress $\left(F_{1,20}=2.75\right.$, n.s.) or anxiety trait $\left(F_{1,20}=2.55\right.$, n.s. $)$ and no interaction between these factors $\left(F_{1,20}=0.45\right.$, n.s. $)$

\section{Effects of the CRFR1 antagonist NBI30775 on the electrophysiological impact of chronic stress}

In a further experiment, we evaluated whether daily administration of the selective, non-peptide CRFR1 antagonist NBI30775 before each daily stressor would prevent stress-induced alterations in: (i) the effect of CRF on fPSP amplitude in the BLA, (ii) stress-related behaviors and (iii) hippocampal cell proliferation. As in previous experiments,
A)

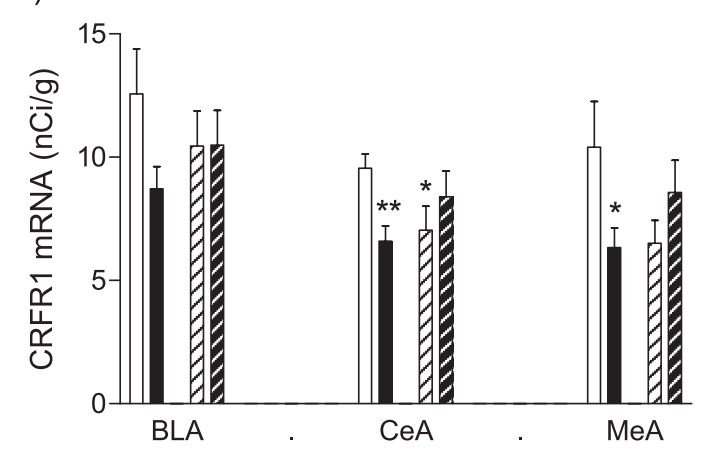

B)
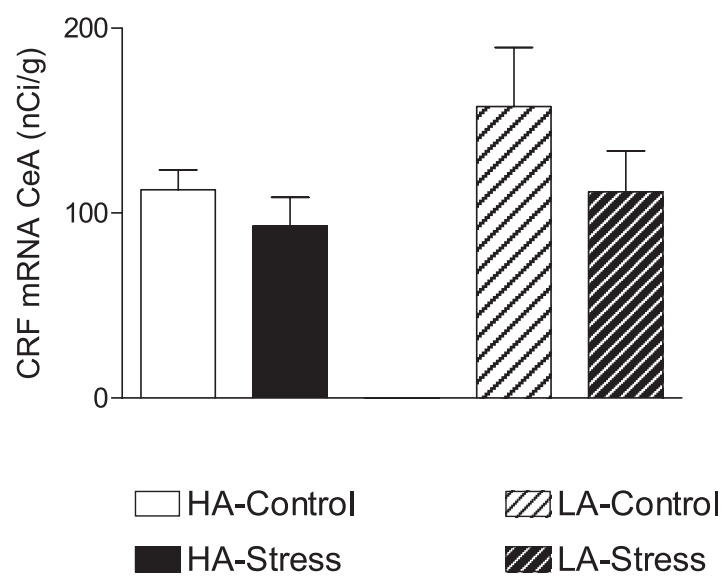

FIG. 3. Impact of CUS on amygdaloid CRF systems according to anxiety trait. In-situ hybridization experiments indicated a stress-induced downregulation of CRFR1 mRNA in the amygdala in (A) HA but not (B) LA rats. No evidence of a modulation of CRF mRNA in the CeA was observed in HA or LA rats. MeA, medial nucleus of the amygdala. ${ }^{*} P<0.05$ and $* * P<0.01$ vs. HA-Control.

analysis of body weight was conducted, in this case using three-way repeated measures ANOVA with anxiety trait, stress and drug as between-subject factors, and time as a within-subject factor [\% Gain: Control + Vehicle group $(n=18)$ : 1 st week, $104.61 \pm 0.34 ; 2$ nd week, $109.24 \pm 0.49$; 3rd week, $112.49 \pm 0.55$; Control + NBI30775 group $(n=19)$ : 1 st week, $104.05 \pm 0.74 ; 2$ nd week, $108.14 \pm 0.77$; 3rd week, $111.31 \pm 0.90$; CUS + Vehicle group $(n=20)$ : 1 st week, $102.76 \pm 0.34 ;$ 2nd week, $103.68 \pm 1.07$; 3rd week, $108.35 \pm 0.75$; CUS + NBI30775 group $(n=20): 1$ st week, $104.47 \pm 1.26 ; 2$ nd week, $106.77 \pm 1.43$; 3 rd week, $110.08 \pm 1.56]$. Significant main effects were found for stress $\left(F_{1,69}=6.79, P<0.011\right)$ and time $\left(F_{2,138}=257.66, P<0.001\right)$. No significant effects of anxiety trait or drug were observed and there were no significant interactions between the factors.

At the end of the CUS procedure, approximately half of the animals from each experimental condition were used for electrophysiological and behavioral analyses, whereas the other half were prepared for evaluation of hippocampal cell proliferation.

Electrophysiology experiments were conducted to determine the effect of CRF on evoked fPSPs in the BLA $24 \mathrm{~h}$ after the final CUS challenge. Analysis of the percent increase in fPSP amplitude produced by CRF $(0.1 \mu \mathrm{M})$ was conducted using a two-way ANOVA with stress and drug as between-subject factors. Consistent with the first experiment described above, a significant effect of stress was 
A)

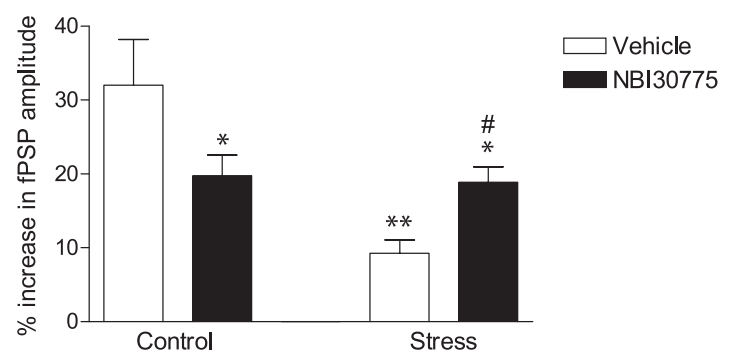

B)

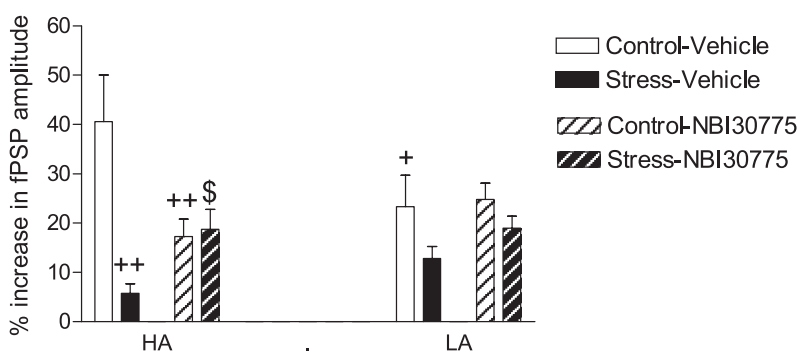

FIG. 4. Effects of the CRFR1 antagonist NBI30775 on the electrophysiological responses to ex-vivo CRF stimulation in the BLA in control and stressed rats. (A) Effect of CRF on the amplitude of fPSPs evoked in slices taken from Control-Vehicle and Control-NBI30775-treated rats, and from Stress-Vehicle and StressNBI30775-treated rats. Stressed animals injected with vehicle showed a reduction in the fPSP amplitude. Although to a lesser extent, NBI30775 treatment also reduced the enhancement of fPSPs by CRF. Moreover, NBI30775 partially reduced the magnitude of the stress-induced decrease of the fPSP amplitude to CRF stimulation. (B) When data were split according to the animals' pre-stress anxiety levels, HA animals showed both the reported downregulation by CUS in fPSP amplitude and a reduction in this response in animals treated with the antagonist (both control and stressed) as compared with the Control-Vehicle group. In HA rats, the antagonist partially reversed the stress-induced downregulation in fPSP amplitude. No significant effects of either CUS or NBI30775 were observed in LA rats but control LA rats showed lower fPSP amplitude than control HA rats (i.e. Control-Vehicle). ${ }^{*} P<0.05$ and $* * P<0.01$ vs. Control-Vehicle; ${ }^{*} P<0.05$ vs. StressVehicle; ${ }^{+} P<0.05$ and ${ }^{++} P<0.01$ vs. HA-Control-Vehicle; ${ }^{\$} P<0.05$ vs. HA-Stress-Vehicle.

observed $\left(F_{1,32}=11.9, P<0.002\right)$. There was no main effect of $\operatorname{NBI30775}\left(F_{1,32}=0.16\right.$, n.s. $)$; however, a significant interaction between stress and drug was observed $\left(F_{1,32}=10.3, P<0.003\right.$; Fig. 4A). Post-hoc analyses indicated that, consistent with the first experiment, the enhancement of fPSP amplitude in the BLA by CRF was significantly reduced by CUS (control + vehicle vs. stress + vehicle, $P<0.001)$. NBI30775 prevented the reduction in response induced by CUS; in the stress groups, NBI30775-treated rats showed a higher percent increase in fPSP amplitude to CRF stimulation than vehicle-treated rats $(P<0.05)$. Finally, in the non-stressed groups, the increase in fPSP amplitude produced by CRF was reduced by NBI30775 treatment compared with vehicle-injected rats $(P<0.02)$.

In a further analysis, the influence of anxiety trait on the electrophysiological response to CRF was considered (Fig. 4B). A three-way ANOVA, with anxiety trait, stress and drug as betweensubject factors, showed once again a significant main effect of stress $\left(F_{1,28}=14.93, P<0.001\right)$. A main effect of anxiety trait or drug was not observed and neither was there a significant interaction between stress and anxiety trait. However, significant interactions between anxiety and drug $\left(F_{1,28}=6.02, P<0.021\right)$, and between stress and drug $\left(F_{1,28}=10.21, P<0.003\right)$ were observed. No statistical differences were found for any other interactions; however, the subdivision by anxiety trait resulted in quite low numbers of subjects in some groups $(n=4-6)$. Post-hoc analyses confirmed previous observations indicating a correlation between the stress-induced reduction in electrophysiological response to CRF and anxiety trait. Specifically, HA rats that were not administered NBI30775 (i.e. HA-StressVehicle) showed the most dramatic reduction in electrophysiological response to $\mathrm{CRF}(P<0.001$ vs. HA-Control-Vehicle), whereas a smaller stress-induced reduction was observed in LA animals that did not reach significance when compared with LA-Control-Vehicle rats (n.s.). As a result, a significant effect of NBI30775 treatment was observed only in HA animals: (i) in the absence of stress the antagonist was associated with a significant reduction in the electrophysiological response to CRF (HA-Control-Vehicle vs. HAControl-NBI30775, $P<0.001$ ); and (ii) in animals submitted to CUS, the antagonist partially reversed the stress-induced decrease in the CRF response, with animals in the HA-Stress-NBI30775 group showing larger responses to CRF than rats in the HA-Stress-Vehicle group $(P<0.05)$. Finally, a significant difference was also found within the vehicle-treated non-stressed rats (Control-Vehicle), with post-hoc analyses indicating larger CRF responses in HA compared with LA rats $(P<0.016)$

\section{Effects of the CRFR1 antagonist NBI30775 on the behavioral impact of chronic stress}

Time spent freezing during the two sessions of the fear conditioning test, conducted on days 20 and 21 of the CUS, was analysed using a repeated measures ANOVA (vehicle, $n=10$; NBI30775, $n=10$ ) with drug as a between-subject factor and session as a within-subject factor. A significant main effect of session $\left(F_{1,18}=14.87, P<0.001\right)$ was observed, consistent with acquisition of the conditioned response. There was no significant main effect of drug $\left(F_{1,18}=2.89\right.$, n.s. $)$; furthermore, there was no significant interaction between drug and session $\left(F_{1,18}=0.044\right.$, n.s.; Fig. 5A). In a further analysis that included anxiety trait as a between-subject factor (Fig. 5B), a two-way repeated measures ANOVA confirmed the significant effect of session $\left(F_{1,16}=13.75, P<0.002\right)$ and a lack of a main effect of anxiety trait $\left(F_{1,16}=0.35\right.$, n.s. $)$; however, there was a trend towards a significant effect of drug $\left(F_{1,16}=3.02, P=0.10\right)$ and for an interaction between anxiety trait and drug $\left(F_{1,16}=2.44, P=0.13\right)$ but not for other potential interactions (all n.s.). The tendency towards significance of an anxiety trait by drug interaction reflects significantly less freezing during the training and testing sessions of the HA rats treated with NBI30775 $(P<0.02)$, which was not observed in LA animals (n.s.), as indicated by a separate ANOVA and post-hoc analyses for each group classified according to anxiety trait.

Time spent floating during the first $5 \mathrm{~min}$ of testing in the forced swimming test on days 7 and 14 was analysed using a two-way repeated measures ANOVA with drug as a between-subject factor and day (7 or 14) as a within-subject factor. Significant main effects of drug $\left(F_{1,18}=4.87, P<0.04\right)$ and day $\left(F_{1,18}=396.47, P<0.0001\right)$ were observed but no significant interaction was observed between them $\left(F_{1,18}=0.04\right.$, n.s.; Fig. $\left.5 \mathrm{C}\right)$. Thus, NBI30775 significantly reduced the percent time spent floating across both test days. Student's $t$-tests for each session indicated a tendency for NBI30775 to reduce floating time on day $7(P=0.06)$ and a significant effect on day $14(P<0.04)$. When a further analysis was conducted, taking into account anxiety trait (Fig. 5D), a two-way repeated measures ANOVA, with anxiety trait included as a between-subject 
A)

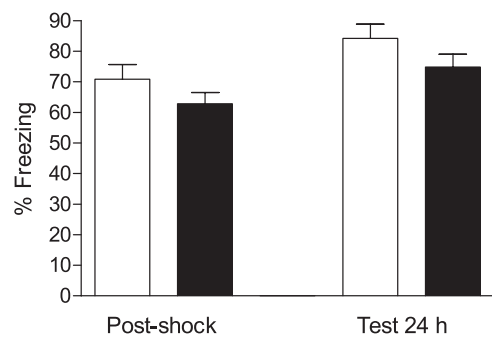

C)

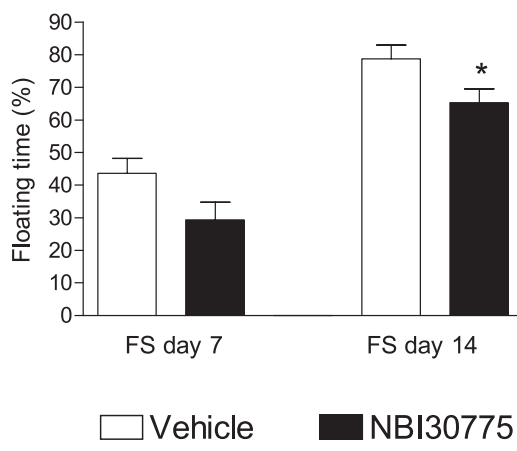

B)

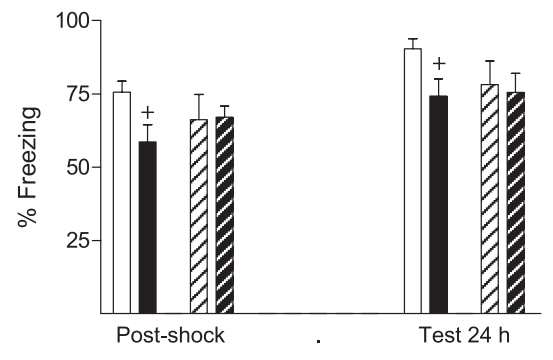

D)

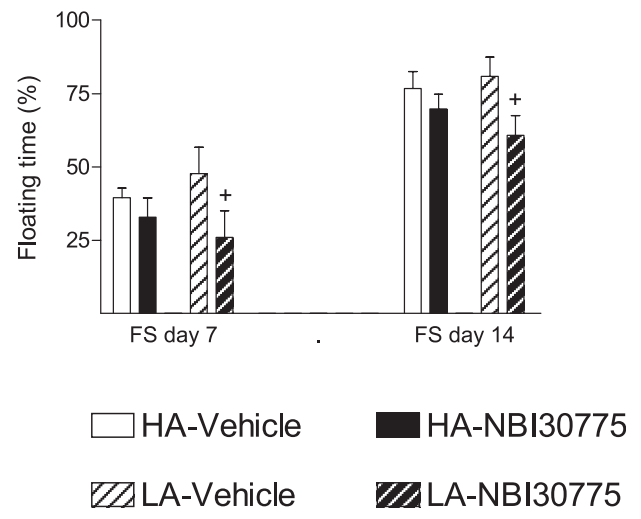

FIG. 5. Effects of the CRFR1 antagonist NBI30775 on the behavioral impact of chronic stress. (A) The contextual fear conditioning test performed on days 20 and 21 did not reveal an effect for NBI30775 treatment when all animals were considered. (B) However, in HA animals, NBI30775 treatment reduced the freezing responses displayed in these chronically stressed rats, whereas it had no effect on LA rats. (C) Histogram showing percent time floating during the first 5 min of the forced swimming tests (FSs) delivered on days 7 and 14 of the CUS. NBI30775 treatment reduced the percent time that rats floated. (D) When animals were split according to anxiety levels, the antagonist was effective in reducing floating levels in LA rats. ${ }^{*} P<0.05$ vs. Vehicle group same session; ${ }^{+} P<0.05$ vs. corresponding Vehicle group same anxiety level.

factor, significant main effects of drug $\left(F_{1,16}=4.665, P<0.046\right)$ and day $\left(F_{1,16}=369.71, P<0.001\right)$ were confirmed but no main effect of anxiety trait was observed $\left(F_{1,16}=0.02\right.$, n.s. $)$ or an interaction between any of the factors (all n.s.). When each session was analysed separately, a significant effect was revealed between LA-Vehicle and LA-NBI30775 groups for each testing day (both $P<0.05)$.

In the remaining half of the animals from this experiment $(n=8-10$ rats per group), we examined the impact of CUS and NBI30775 on cell proliferation in the dentate gyrus of the hippocampus. The number of Ki67-immunoreactive cells in sections of the dentate gyrus was analysed using a two-way ANOVA with stress and drug as betweensubject factors. A significant main effect of both stress $\left(F_{1,35}=4.224\right.$, $P<0.047)$ and drug $\left(F_{1,35}=4.98, P<0.033\right)$ was observed but no interaction between them $\left(F_{1,35}=1.45\right.$, n.s. $)$. Thus, stress was associated with a reduction and NBI30775 was associated with an increase in cell proliferation (Fig. 6A). Post-hoc analyses indicated that cell proliferation for the control + NBI30775 group was significantly higher than for each of the other groups $(P<0.05)$. Examples of the immunohistochemical labeling under the different experimental conditions are shown in Fig. 7. Double-labeling experiments showed coincidental labeling for CRFR1 and NeuN (Fig. 7) but not for CRFR1 and the proliferation marker Ki67 (Fig. 7), indicating a localization of the CRFR1 in mature, but not new, hippocampal neurons.
In a subsequent three-way ANOVA, anxiety trait was included as a between-subject factor (Fig. 6B). Significant main effects of stress $\left(F_{1,27}=6.96, P<0.014\right)$ and $\operatorname{drug}\left(F_{1,27}=5.21, P<0.031\right)$ were confirmed but there was no significant main effect of anxiety trait $\left(F_{1,27}=0.10\right.$, n.s.). However, significant interactions between anxiety trait and stress $\left(F_{1,27}=8.69, P<007\right)$ and between anxiety trait and drug $\left(F_{1,27}=7.41, P<011\right)$ were observed. None of the other potential interactions were significant. Post-hoc analyses indicated that: (i) in vehicle-treated animals, the CUS procedure induced a significant reduction in cell proliferation in HA rats (compared with unstressed HA rats, $P<0.05$ ) that was not observed in LA rats (stressed vs. control LA animals, n.s.); and (ii) in the absence of stress, NBI30775 increased cell proliferation only in HA rats (compared with vehicle-treated HA animals, $P<0.01$ ), having no effect on proliferation in LA rats (drug-treated vs. vehicle-treated LA animals, n.s.). Furthermore, cell proliferation in HA and LA rats differed significantly, with HA rats showing greater proliferation than LA rats $(P<0.01)$. A subsequent two-way ANOvA, with stress and drug as between-subject factors, performed on the proliferation results from animals with each anxiety trait separately, indicated a lack of effect of either stress or drug on hippocampal cell proliferation among the LA animals. However, significant main effects of stress $\left(F_{1,13}=14.46\right.$, $P<0.003)$ and drug $\left(F_{1,13}=11.60, P<0.005\right)$ were observed among the HA rats, although once again there was no interaction between the two factors $\left(F_{1,13}=0.68\right.$, n.s. $)$. Thus, this analysis suggests that the 
A)

ALL ANIMALS

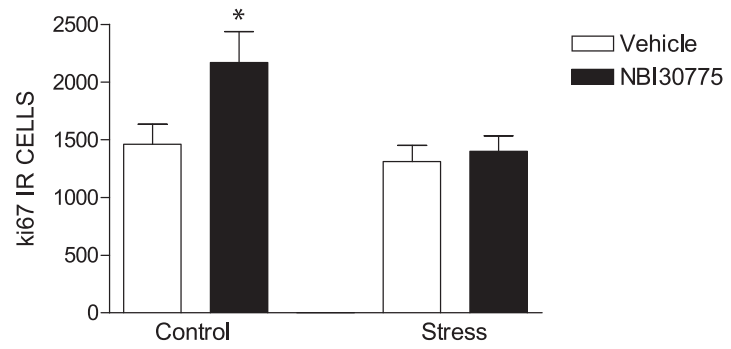

B)

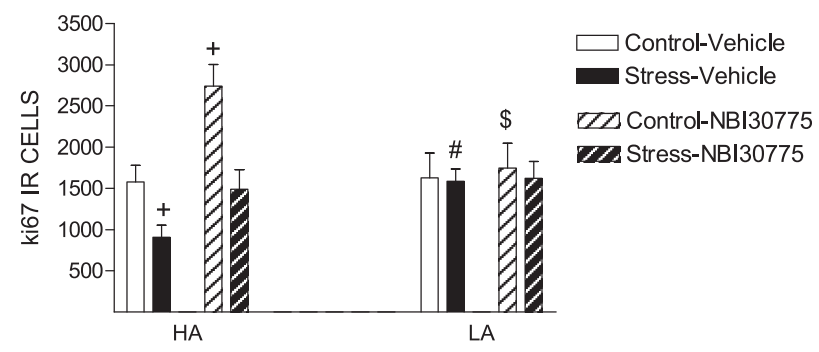

FIG. 6. Effects of the CRFR1 antagonist NBI30775 and chronic stress on hippocampal cell proliferation. Number of Ki67-immunoreactive (IR) cells in the dentate gyrus of the hippocampus after CUS. (A) The CRFR1 antagonist NBI30775 increased cell proliferation in Control-Vehicle animals. (B) When animals were split according to their anxiety levels, in HA rats, CUS decreased the number of newly generated cells and treatment with NBI30775 prevented the reduction. In HA rats, NBI30775 substantially increased cell proliferation in control, unstressed rats. In rats previously characterized as LA, no effect of the drug or stress was observed but LA rats submitted to stress (vehicle) showed higher proliferation levels than HA stressed (vehicle) rats and control unstressed rats injected with the antagonist had lower proliferation levels than HA control unstressed rats. ${ }^{*} P<0.05$ vs. all other groups; ${ }^{+} P<0.01$ vs. HA-Stress-Vehicle; ${ }^{\#} P<0.05$ vs. HA-Stress-Vehicle; ${ }_{P} P<0.01$ vs. HA-Control-NBI307775.

previous finding regarding the negative and positive effects of stress and NBI30775 on cell proliferation, respectively $(P<0.05$ in each case), is particular to HA rats (Fig. 6B).

\section{Discussion}

In the present study, our goal was to evaluate whether chronic stress might alter the BLA electrophysiological response to CRF and whether this might be influenced by the animals' anxiety trait. We also set out to determine whether a CRFR1 antagonist, given during the CUS procedure, might prevent the effects of stress on electrophysiological responses. Using a 3 week CUS protocol, we show here that the potentiating effect of CRF on evoked fPSPs in the BLA is significantly reduced in chronically stressed rats. This reduction is accompanied by behavioral changes that validate the chronic stress procedure; stressed animals showed enhanced contextual fear conditioning, as previously shown for other chronic stress protocols (Sandi et al., 2001; Cordero et al., 2003), and increased depression-like behavior (immobility in the forced swimming test) over the course of the CUS procedure. Moreover, the percent increase in immobilization across the CUS procedure correlated with the inhibition of the potentiating effect of CRF on evoked fPSPs in the BLA induced by stress, i.e. the higher the percent increase in immobilization, the lower the percent increase in fPSP amplitude. Our results reinforce the view that chronic stress reduces sensitivity to CRF, as suggested by recent work in which chronic stress attenuated behavioral responses induced by intracerebroventricular administration of CRF and induced depression-like behavior in the forced swim test (Swiergiel et al., 2008).

Interestingly, we also found that the degree of reduction of CRFinduced facilitation of fPSP was dependent upon the animals' trait anxiety, with the reduction in the enhancing effect of CRF being particularly evident in highly anxious rats. These results suggest a vulnerability of high trait anxiety individuals to develop alterations in amygdaloid CRF systems under exposure to chronic stress. These results fit with a growing body of data indicating that high trait anxiety is a vulnerability factor for diverse psychiatric alterations due to stress and may be especially relevant in patients with generalized anxiety disorder or major depression (Chambers et al., 2004).

Emotional responses are well known to be regulated by the amygdala, where stress has been repeatedly shown to induce CRF release (Koob \& Heinrichs, 1999), which is followed by subsequent activation of CRFRs and which leads to alterations in emotional behavior (Dunn \& Berridge, 1990; Lee \& Davis, 1997; Sajdyk \& Gehlert, 2000). In vivo, CRF is released in the BLA by afferents from the CeA (Swanson et al., 1983; Roozendaal et al., 2002). Cumulative evidence indicates that activation of CRFR1 in the BLA is critical for attributing emotional salience to potentially anxiogenic or aversive stimuli (Sajdyk et al., 1999; Roozendaal et al., 2002; Shekhar et al., 2005) and appears to be essential for the consolidation of emotional memories (Paré et al., 2004). Stress-induced plasticity within the BLA has been proposed as a critical step in the development of chronic anxiety-related disorders (Rainnie et al., 2004; Shekhar et al., 2005). Several studies of depressed humans have observed hyperactivation of the amygdala at rest or in response to an emotional stimulus (Drevets, 2000; Sheline et al., 2001; Siegle et al., 2002, 2007). The amygdala response to emotional stimuli in these patients was found to predict the outcome of antidepressant treatment, with evidence suggesting that greater amygdala activation to emotional stimuli is associated with greater symptom improvement 8 months later (Canli et al., 2005). Furthermore, in depressed patients, behavioral, cognitive and autonomic studies indicate that those patients that are more reactive to emotional stimuli exhibit greater symptomatic improvement than do individuals who show little emotional reactivity (Kasch et al., 2002; Rottenberg et al., 2002). In the present study, rats characterized as highly anxious were those that showed the smallest response to CRF in the BLA following exposure to chronic stress. Therefore, we can speculate that the reduction in amygdala response to CRF caused by chronic stress might underlie the clinical observation of the relationship between emotional reactivity and treatment outcome in depressed patients. Furthermore, our results suggest that high trait anxiety might predispose patients to a poorer prognosis. Although, to our knowledge, the influence of anxiety trait on treatment outcomes has not been investigated in depressed patients, patients with Parkinson's disease with HA show evidence for reduced amygdala response to emotional stimuli, inferred from a blunted startle response to aversive pictures (Bowers et al., 2006).

With the exception of a study conducted with the CRFR1 antagonist, NB130775 (Zobel et al., 2000), there has been no clinical evaluation of the efficacy of this class of drug in patients with depression. However, the present results provide a strong motivation to do this. The results show that treatment with NBI30775 during exposure to CUS prevented both the electrophysiological and 

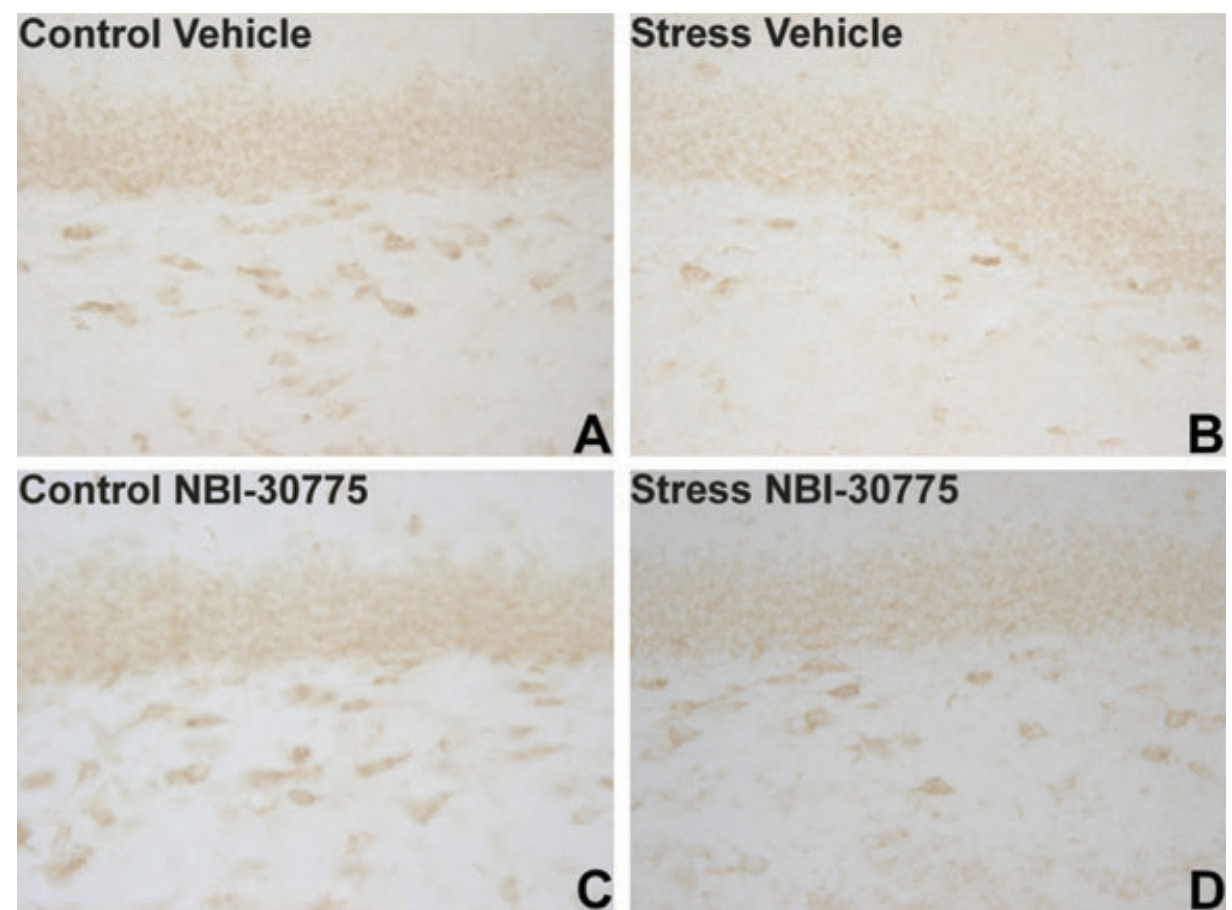

Stress NBI-30775
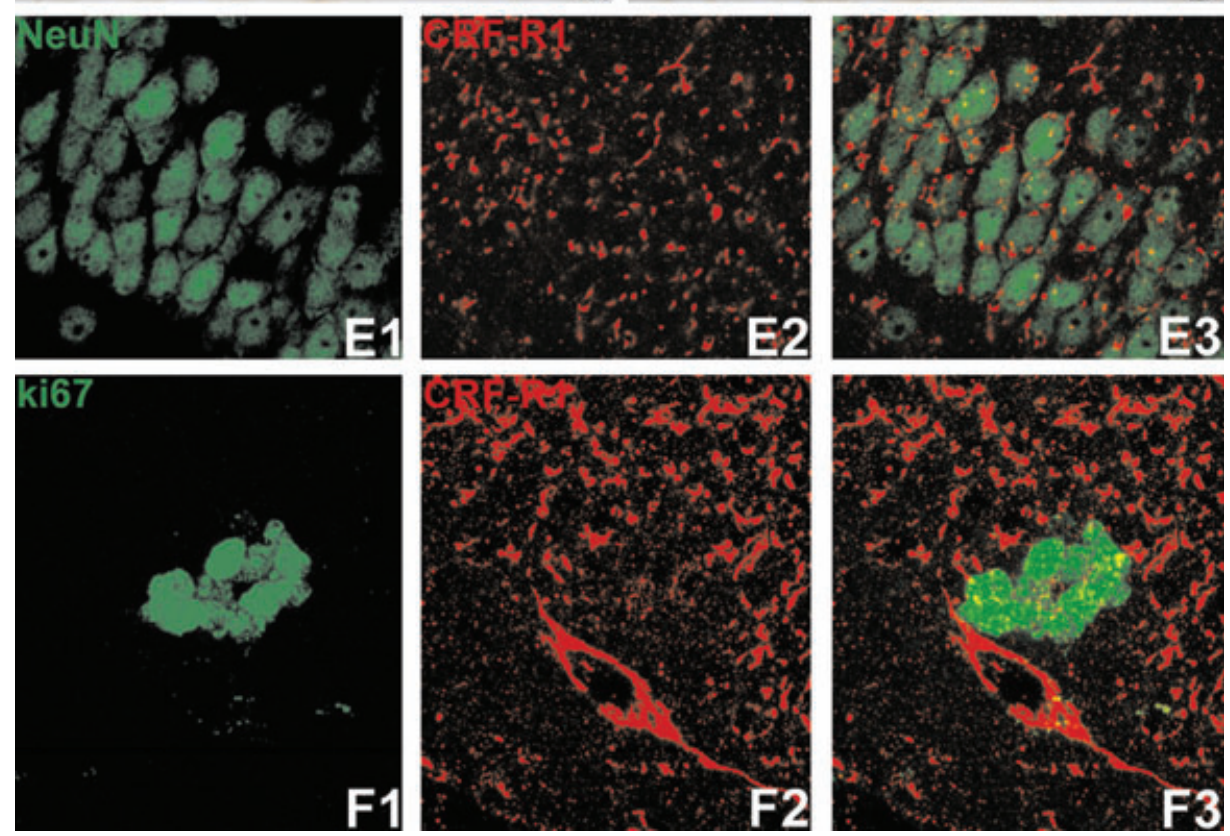

FIG. 7. Microphotographs showing changes in CRFR1 expression in the granule cell layer of the dentate gyrus following CUS and/or treatment with CRFR1 antagonist (A-D). Characterisation of the phenotype of CRFR1-immunoreactive cells in the dentate gyrus: (E) Neurons positive for Neun (E1, Green) express CRFR1 (E2, red). (F) Newly generated cells positive for ki67 (F1, green) are devoid of CRFR1 expression (F2, red). E3 and F3 show overlays.

behavioral alterations induced by stress. Furthermore, when considering the animals' trait anxiety, treatment with NBI30775 had the most marked effect on HA rats, with less effect in the LA animals (although they were more sensitive to the drug in the forced swimming test), although of course the LA rats were less affected by the CUS in the first place. Furthermore, the electrophysiological response to CRF of unstressed HA controls was approximately double the response observed in LA controls. Thus, we can speculate that highly anxious animals are characterized by a strong influence of CRF on excitability of the BLA but this influence is particularly susceptible to reduction by stress. However, treatment with a CRFR1 antagonist may normalize the influence of CRF in highly anxious animals and render them more resistant to the effects of stress. Consistent with the electrophysiological findings, NBI30775 treatment also had a selective effect on the freezing response of HA but not LA animals in the fear conditioning task. In addition, NBI30775 prevented stress-induced reductions in hippocampal cell proliferation, an effect that was again observed in HA but not LA animals. In contrast, the ability of NBI30775 to reduce immobility in the forced swim test was observed in the whole sample and, particularly, in LA animals. Based on these findings, we can speculate that CRFR1 antagonists might be particularly effective in high trait anxiety patients who may be less receptive to existing treatments; however, given the behavioral findings it remains to be seen whether this will be the case for 
patients with depression as well as for patients with anxiety disorders, such as post-traumatic stress disorder.

Several studies have shown that stress inhibits adult hippocampal neurogenesis, a phenomenon that is suggested to be related to depression (Duman, 2004; but see Sahay \& Hen, 2007). Our results indicate a particular vulnerability of high trait anxiety animals to show diminished cell proliferation in the dentate gyrus following chronic stress, which fits with recent rodent studies suggestive of reduced adult hippocampal neurogenesis associated with inhibited emotionality (Earnheart et al., 2007; Leal-Galicia et al., 2007). We also show that the chronic stress-induced reduction in cell proliferation is reversed by chronic treatment with the CRFR1 antagonist, in agreement with a previous study in mice employing another CRFR1 antagonist (Alonso et al., 2004). Moreover, in highly anxious non-stressed animals, NBI30775 increased cell proliferation. Therefore, our results support the view that antagonizing CRFR1 has a similar effect to other classes of antidepressant drugs reported to increase both cell proliferation and neurogenesis in the dentate gyrus of the adult hippocampus following chronic treatment (Malberg \& Blendy, 2005); however, the beneficial effects of CRFR1 antagonists might be dependent to some extent on anxiety trait.

CRFR1 is regarded as a novel target for treating depression, anxiety and other stress-related disorders. In pre-clinical studies, CRFR1 antagonists appear to be more efficacious in animal models in which CRF pathways are hyperactivated, whereas they have little effect in models that are associated with low basal CRF activity (Kehne, 2007). Our results are consistent with the indication that CRFR1 antagonists are more effective in reducing anxiety-like behaviors in rodents with high trait anxiety-like behavior and/or in those animals previously exposed to stress (Lancel et al., 2002; Heinrichs \& Koob, 2004; Keck et al., 2005). Specifically, our results are in line with the recent proposal that 'CRFR1 antagonism pharmacotherapy may be especially effective in the treatment of affectively ill patients experiencing considerable stress - particularly individuals who are either genetically predisposed to develop anxiety disorders or have been exposed to high levels of stress that sensitize subsequent stress responses' (Hauger et al., 2006).

Several studies (not always replicated) in depressed suicide victims have found CRF expression to be increased in different brain regions, whereas CRFR binding sites in the cortex were decreased, suggesting a downregulation of CRF signaling in response to excessive release of the peptide (Risbrough \& Stein, 2006). Overexpression of CRF in genetically engineered mice increases anxiety-like behaviors, whereas a deficiency of CRFR1 is associated with reduced anxiety-like behavior (Arzt \& Holsboer, 2006). Although not a main goal of this study, we evaluated whether amygdaloid CRF systems might be affected by CUS in ways that could help explain the blunting of the electrophysiological response to CRF in chronically stressed animals. We observed a downregulation of CRFR1 mRNA throughout the amygdala in high anxious animals, which may be indicative of hyperactivity of CRF transmission during the chronic stress procedure in high, but not low, anxious rats. This is consistent with previous reports indicating a differential modulation of CRF systems by stress in strains of mice presenting a different vulnerability to stress (Anisman et al., 2007). However, after 3 weeks of CUS, we did not observe significant alterations in CRF mRNA content in the CeA, although this does not preclude the possibility that an upregulation of CRF peptide might have occurred transiently earlier during the stress procedure. In addition, the potential contribution of CUS-induced effects on neuronal architecture in the BLA, as previously described for other chronic stress procedures (Mitra et al., 2005), cannot be discarded.
In summary, we report evidence for a link between trait anxiety and reduction in the electrophysiological response of the BLA to CRF following chronic stress, with highly anxious animals showing a blunted response. Moreover, we present morphological and pharmacological evidence that implicates CRFR1 receptors in these chronic stress-induced alterations and suggests that chronic treatment with a CRFR1 antagonist can protect the brain from some of the effects of chronic stress. Our study points at CRF and CRFR1 systems as potential mechanistic links between high trait anxiety and vulnerability to develop depression under conditions of chronic stress.

\section{Acknowledgements}

This work was partially supported by intramural funding from the EPFL (Switzerland) and grants from the Swiss National Science Foundation (3100A0-108102) and the FP6 (PROMEMORIA, 2003-512012) and FP7 (MemStick, HEALTH-F2M-2007-201600) EU Projects to C.S. The authors would like to thank Dr Dimitri Grigoriadis, Neurocrine Biosciences Inc., for the donation of the CRFR1 antagonist NBI30775.

\section{Abbreviations}

BLA, basolateral nucleus of the amygdala; CeA, central nucleus of the amygdala; CRF, corticotropin-releasing factor; CRFR, corticotropin-releasing factor receptor; CUS, chronic unpredictable stress; EPM, elevated plus maze; fPSP, field post-synaptic potential; HA, high anxiety; LA, low anxiety; n.s., not significant; NBI30775, 3-[6-(dimethylamino)-4-methyl-pyrid-3-yl]-2,5dimethyl-N,N-dipropyl-pyrazolo[2,3-a]pyrimidin-7-amine; NeuN, neuronal nuclear protein; PBS, phosphate-buffered saline.

\section{Financial disclosure}

A.U., L.C. and C.H.L. are full-time employees of GSK S.p.A.

\section{References}

Alonso, R., Griebel, G., Pavone, G., Stemmelin, J., Le Fur, G. \& Soubrié, P. (2004) Blockade of CRF1 or V1b receptors reverses stress-induced suppression of neurogenesis in a mouse model of depression. Mol. Psychiatry, 9, 278-286.

Anisman, H., Prakash, P., Merali, Z. \& Poulter, M.O. (2007) Corticotropin releasing hormone receptor alterations elicited by acute and chronic unpredictable stressor challenges in stressor-susceptible and resilient strains of mice. Behav. Brain Res., 181, 180-190.

Arborelius, L., Owens, M.J., Plotsky, P.M. \& Nemeroff, C.B. (1999) The role of corticotropin-releasing factor in depression and anxiety disorders. J. Endocrinol., 160, 1-12.

Arborelius, L., Skelton, K.H., Thrivikraman, K.V., Plotsky, P.M., Schulz, D.W. \& Owens, M.J. (2000) Chronic administration of the selective corticotropin-releasing factor 1 receptor antagonist CP-154,526: behavioral, endocrine and neurochemical effects in the rat. J. Pharmacol. Exp. Ther, 294, 588-597.

Arzt, E. \& Holsboer, F. (2006) CRF signaling: molecular specificity for drug targeting in the CNS. Trends Pharmacol. Sci., 27, 531-538.

Bale, T.L. \& Vale, W.W. (2003) Increased depression-like behaviors in corticotropin-releasing factor receptor-2-deficient mice: sexually dichotomous responses. J. Neurosci., 23, 5295-5301.

Ball, S.A. \& Schottenfeld, R.S. (1997) A five-factor model of personality and addiction, psychiatric, and AIDS risk severity in pregnant and postpartum cocaine misusers. Subst. Use Misuse, 32, 25-41.

Blank, T., Nijholt, I., Eckhart, K. \& Spiess, J. (2002) Priming of long-term potentiation in mouse hippocampus by corticotropin-releasing factor and acute stress: implications for hippocampus-dependent learning. J. Neurosci., 22, 3788-3794.

Bowers, D., Miller, K., Mikos, A., Kirsch-Darrow, L., Springer, U., Fernandez, H., Foote, K. \& Okun, M. (2006) Startling facts about emotion in Parkinson's disease: blunted reactivity to aversive stimuli. Brain, 129, 3356-3365 
Canli, T., Cooney, R.E., Goldin, P., Shah, M., Sivers, H., Thomason, M.E., Whitfield-Gabrieli, S., Gabrieli, J.D.E. \& Gotlib, I.H. (2005) Amygdala reactivity to emotional faces predicts improvement in major depression. Neuroreport, 16, 1267-1270.

Chambers, J.A., Power, K.G. \& Durham, R.C. (2004) The relationship between trait vulnerability and anxiety and depressive diagnoses at longterm follow-up of generalized anxiety disorder. J. Anxiety Disord., 18, 587607.

Chen, Y., Brunson, K.L., Muller, M.B., Cariaga, W. \& Baram, T. (2000) Immunocytochemical distribution of corticotropini-releasing hormone receptor type-1 (CRF1)-like immunoreactivity in the mouse brain: light microscopy analysis using an antibody directed against the C-terminus. J. Comp. Neurol., 420, 305-323.

Cordero, M.I., Kruyt, N.D. \& Sandi, C. (2003) Modulation of contextual fear conditioning by chronic stress in rats is related to individual differences in behavioral reactivity to novelty. Brain Res., 970, 242-245.

Drevets, W.C. (2000) Neuroimaging studies of mood disorders. Biol. Psychiatry, 48, 813-829.

Dube, T., Brunson, T., Nehlig, A. \& Baram, T.Z. (2000) Activation of specific neuronal circuits by corticotropin releasing hormone as indicated by c-fos expression and glucose metabolism. J. Cereb. Blood Flow Metab., 20, 1414 1424.

Duman, R.S. (2004) Depression: a case of neuronal life and death? Biol. Psychiatry, 56, 140-145.

Dunn, A.J. \& Berridge, C.W. (1990) Physiological and behavioral responses to corticotropin releasing factor administration: is CRF a mediator of anxiety or stress responses? Brain Res. Rev., 15, 71-100.

Earnheart, J.C., Schweizer, C., Crestani, F., Iwasato, T., Itohara, S., Mohler, H. \& Lüscher, B. (2007) GABAergic control of adult hippocampal neurogenesis in relation to behavior indicative of trait anxiety and depression states. J. Neurosci., 27, 3845-3854.

Gundersen, H.J. \& Jensen, E.B. (1987) The efficiency of systematic sampling in stereology and its prediction. J. Microsc., 147, 229-263.

Hauger, R.L., Risbrough, V., Brauns, O. \& Dautzenberg, F.M. (2006) Corticotropin releasing factor (CRF) receptor signalling in the central nervous system: molecular targets. CNS Neurol. Disord. Drug Targets, 5, 453-479.

Heinrichs, S.C. \& Koob, G.F. (2004) Corticotropin-releasing factor in brain: a role in activation, arousal, and affect regulation. J. Pharmacol. Exp. Ther, 311, 427-440.

Herrero, A.I., Sandi, C. \& Venero, C. (2006) Individual differences in anxiety trait are related to spatial learning abilities and hippocampal expression of mineralocorticoid receptors. Neurobiol. Learn. Mem., 86, $150-159$.

Holsboer, F. (1999) The rationale for corticotropin-releasing hormone receptor (CRH-R) antagonists to treat depression and anxiety. J. Psychiatr. Res., 33, $181-214$

Isoardi, N.A., Martijena, I.D., Carrer, H.F. \& Molina, V.A. (2004) Increased fear learning coincides with neuronal dysinhibition and facilitated LTP in the basolateral amygdala following benzodiazepine withdrawal in rats. Neuropsychopharmacology, 29, 1852-1864.

Kasch, K.L., Rottenberg, J., Arnow, B.A. \& Gotlib, I.H. (2002) Behavioral activation and inhibition systems and the severity and course of depression. J. Abnorm. Psychol., 111, 589-597.

Keck, M.E., Ohl, F., Holsboer, F. \& Müller, M.B. (2005) Listening to mutant mice: a spotlight on the role of CRF/CRF receptor systems in affective disorders. Neurosci. Biobehav. Rev., 29, 867-889.

Kehne, J.H. (2007) The CRF(1) receptor, a novel target for the treatment of depression, anxiety and stress-related disorders. CNS Neurol. Disord. Drug Targets, 6, 163-182.

Koob, G.F. \& Heinrichs, S.C. (1999) A role for corticotropin releasing factor and urocortin in behavioral responses to stressors. Brain Res., 848, 141152.

Lancel, M., Muller-Preuss, P., Wigger, A., Landgraf, R. \& Holsboer, F. (2002) The CRH1 receptor antagonist R121919 attenuates stress-elicited sleep disturbances in rats, particularly in those with high innate anxiety. J. Psychiatr. Res., 36, 197-208.

Leal-Galicia, P., Saldívar-González, A., Morimoto, S. \& Arias, C. (2007) Exposure to environmental enrichment elicits differential hippocampal cell proliferation: role of individual responsiveness to anxiety. Dev. Neurobiol., 67, 395-405.

Lee, Y. \& Davis, M. (1997) Role of the hippocampus, the bed nucleus of the stria terminalis, and the amygdala in the excitatory effect of corticotropinreleasing hormone on the acoustic startle reflex. J. Neurosci., 17, 64346446.
Levinson, D.F. (2006) The genetics of depression: a review. Biol. Psychiatry, 60, 84-92.

Malberg, J.E. \& Blendy, J.A. (2005) Antidepressant action: to the nucleus and beyond. Trends Pharmacol. Sci., 26, 631-638.

McGaugh, J.L. (2004) The amygdala modulates the consolidation of memories of emotionally arousing experiences. Аппи. Rev. Neurosci., 27, $1-28$.

Merlo Pich, E., Lorang, M., Yeganeh, M., Rodriguez de Fonseca, F., Raber, J., Koob, G.F. \& Weiss, F. (1995) Increase of extracellular corticotropinreleasing factor-like immunoreactivity levels in the amygdala of awaked rats during restraint stress and ethanol withdrawal as measured by midrodialysis. J. Neurosci., 15, 5439-5447.

Mitra, R., Jadhav, S., McEwen, B.S., Vyas, A. \& Chattarji, S. (2005) Stress duration modulates the spatiotemporal patterns of spine formation in the basolateral amygdala. Proc. Natl Acad. Sci. USA, 102, 93719376.

Paré, D. (2003) Role of the basolateral amygdala in memory consolidation. Prog. Neurobiol., 70, 409-420.

Paré, D., Quirk, G.J. \& Ledoux, J.E. (2004) New vistas on amygdala networks in conditioned fear. J. Neurophysiol., 92, 1-9.

Paxinos, G. \& Watson, C.. (1998) The Rat Brain in Stereotaxic Coordinates, 4th Edn. Academic Press, San Diego, USA.

Rainnie, D.G., Fernhout, B.J. \& Shinnick-Gallagher, P. (1992) Differential actions of corticotropin releasing factor on basolateral and central amygdaloid neurons, in vitro. J. Pharmacol. Exp. Ther, 263, 846858.

Rainnie, D.G., Bergeron, R., Sajdyk, T.J., Patil, M., Gehlert, D.R. \& Shekhar, A. (2004) Corticotrophin releasing factor-induced synaptic plasticity in the amygdala translates stress into emotional disorders. J. Neurosci., 24, 34713479.

Risbrough, V.B. \& Stein, M.B. (2006) Role of corticotropin releasing factor in anxiety disorders: A translational research perspective. Horm. Behav, 50, $550-561$.

Roozendaal, B., Brunson, K.L., Holloway, B.L., McGaugh, J.L. \& Baram, T.Z. (2002) Involvement of stress-released corticotropin-releasing hormone in the basolateral amygdala in regulating memory consolidation. Proc. Natl Acad. Sci. USA, 99, 13908-13913.

Roozendaal, B., Hahn, E.L., Nathan, S.V., de Quervain, D.J. \& McGaugh, J.L. (2004) Glucocorticoid effects on memory retrieval require concurrent noradrenergic activity in the hippocampus and basolateral amygdala. J. Neurosci., 24, 8161-8169.

Rottenberg, J., Kasch, K.L., Gross, J.J. \& Gotlib, I.H. (2002) Sadness and amusement reactivity differentially predict concurrent and prospective functioning in major depressive disorder. Emotion, 2, 135-146.

Sahay, A. \& Hen, R. (2007) Adult hippocampal neurogenesis in depression. Nat. Neurosci., 10, 1110-1115.

Sajdyk, T.J. \& Gehlert, D.R. (2000) Astressin, a corticotropin releasing factor antagonist, reverses the anxiogenic effects of urocortin when administered into the basolateral amygdala. Brain Res., 877, 226-234.

Sajdyk, T.J., Schober, D.A., Gehlert, D.R. \& Shekhar, A. (1999) Role of corticoptropin-releasing factor and urocortin within the basolateral amygdala of rats in anxiety and panic responses. Behav. Brain Res., 100, 207215

Sandi, C., Merino, J.J., Cordero, M.I., Touyarot, K. \& Venero, C. (2001) Effects of chronic stress on contextual fear conditioning and the hippocampal expression of the neural cell adhesion molecule, its polysialylation, and L1. Neuroscience, 102, 329-339.

Shekhar, A., Truitt, W., Rainnie, D. \& Sajdyk, T. (2005) Role of stress, corticotropin releasing factor (CRF) and amygdala plasticity in chronic anxiety. Stress, 8, 209-219.

Sheline, Y.I., Barch, D.M., Donnelly, J.M., Ollinger, J.M., Snyder, A.Z. \& Mintun, M.A. (2001) Increased amygdala response to masked emotional faces in depressed subjects resolves with antidepressant treatment: an fMRI study. Biol. Psychiatry, 50, 651-658.

Siegle, G.J., Steinhauer, S.R., Thase, M.E., Stenger, V.A. \& Carter, C.S. (2002) Can't shake that feeling: event-related fMRI assessment of sustained amygdala activity in response to emotional information in depressed individuals. Biol. Psychiatry, 51, 693-707.

Siegle, G.J., Thompson, W., Carter, C.S., Steinhauer, S.R. \& Thase, M.E. (2007) Increased amygdala and decreased dorsolateral prefrontal BOLD response in unipolar depression: related and independent features. Biol. Psychiatry, 61, 198-209.

Southwick, S.M., Vythilingam, M. \& Charney, D.S. (2005) The psychobiology of depression and resilience to stress: implications for prevention and treatment. Annu. Rev. Clin. Psychol., 1, 255-291. 
Swanson, L.W., Sawchenko, P.E., Rivier, J. \& Vale, W.W. (1983) Organization of ovine corticotropin-releasing factor immunoreactive cells and fibers in the rat brain: an immunohistochemical study. Neuroendocrinology, 36, 165-186.

Swiergiel, A.H., Leskov, I.L. \& Dunn, A.J. (2008) Effects of chronic and acute stressors and CRF on depression-like behavior in mice. Behav. Brain Res., 186, 32-40.

Ugolini, A., Sokal, D.M., Arban, R. \& Large, C.H. (2008) CRF1 receptor activation increases the response of neurons in the basolateral nucleus of the amygdala to afferent stimulation. Front. Behav. Neurosci., 2, 2. [doi:10.3389/neuro.08.002.2008].

Van Den Eede, F., Van Broeckhoven, C. \& Claes, S.J. (2005) Corticotropinreleasing factor-binding protein, stress and major depression. Ageing Res. Rev., 4, 213-239.
Van Pett, K., Viau, V., Bittencourt, J.C., Chan, R.K., Li, H.Y., Arias, C., Prins, G.S., Perrin, M., Vale, W. \& Sawchenko, P.E. (2000) Distribution of mRNAs encoding CRF receptors in brain and pituitary of rat and mouse. J. Comp. Neurol., 428, 191-212.

Wang, W., Du, W., Liu, P., Liu, J. \& Wang, Y. (2002) Five-factor personality measures in Chinese university students: effects of one-child policy? Psychiatry Res., 109, 37-44.

West, M.J. (1993) New stereological methods for counting neurons. Neurobiol. Aging, 14, 275-285

Zobel, A.W., Nickel, T., Künzel, H.E., Ackl, N., Sonntag, A., Ising, M. \& Holsboer, F. (2000) Effects of the high-affinity corticotropin-releasing hormone receptor 1 antagonist R121919 in major depression: the first 20 patients treated. J. Psychiatr. Res., 34, 171-181. 